\title{
ANGIOMA OF THE LARYNX, ESPECIALLY ITS RELATION TO CHRONIC LARYNGITIS
}

\author{
WITH REPORT OF A CASE IN A CHILD NINE MONTHS OLD, FOLLOWING
}

MEASLES. REVIEW OF THE LITERATURE

\author{
JOHN PHILJIPS, M.B., AND H. O. RUH, M.D. \\ CLEVELAND, 0 .
}

Angioma of the larynx is a very rare condition. In a careful review of the literature we have been able to find twenty-six cases. The following case is therefore considered worthy of report:

History.-Baby H., male, aged 9 months, came under observation August 10, 1912, because of difficulty in breathing. The family history threw no light on the case. The baby had been breast-fed since birth and was well nourished.

The present trouble dated from an attack of measles in May. Following this for a period of one month, there was hoarseness, with some difficulty in breathing, and a "croupy" cough. This gradually improved so that for a period of two or three weeks scarcely any abnormality of breathing could be noticed. Three weeks prior to this report he began to have increased hoarseness, some cough, and dyspnea, the inspiration being accompanied by a stridor. This has grown progressively worse and the only relief that could be given was from large doses of ipecac. Following the vomiting which this produced, the child breathed somewhat easier for a few minutes. His dyspnea has always been worse at night than during the day.

Physical Examination.-The child was unusually well nourished; skin and mucous membranes were cyanotic; it was extremely restless. There was great difficulty in breathing, with loud inspiratory stridor, and marked dilatation of the alae nasi. The tongue was coated, tonsils normal, and there was no bulging of the posterior pharyngeal wall. The child was unable to nurse because of the dif. ficulty in breathing. All the accessory muscles of respiration were brought into play; there was retraction of the supraclavicular spaces and epigastrium, with a marked projection forward of the sternum. The lungs were normal except for an area of dulness at the left base posteriorly, extending from the angle of the scapula to the base. Over the same area there could be made out no abnormality of breathing, because the inspiratory stridor obscured all other sounds. The rate of respiration was 40 to the minute. The heart showed nothing unusual except some enlargement of the left ventricle. The $x$-ray examination of the chest showed no growth in the mediastinum. The pulse-rate was 140 . The rest of the physical examination revealed nothing abnormal. Because of the extreme restlessness no laryngoscopic examination could be made. The temperature was 105 and the leukocyte count was 50,000. Because of the presence of pneumonia and the moribund condition of the child a tracheotomy was not considered advisable. The child grew gradually weaker and died the next day.

\section{NECROPSY PROTOCOL}

Anatomical Diagnosis.-Stenosis of the larynx; chronic catarrhal laryngitis; chronic inflammatory hyperplasia of the laryngeal mucosa; hemangioma simplex of the larynx; early lobar pneumonia of the lower lobe of the left lung; slight fragmentation of the myocardium; slight hypertrophy of left ventricle. 
Inspection.-The body is that of a well developed, well nourished child of 9 months. Rigor mortis is slight. There is a moderate amount of post mortem staining in dependent portions. The skin is soft and free from scars, pigmentations or edema. There is a slight dusky hue around the face and neck. The superficial lymph-nodes are not enlarged. The head is well formed. The eyes, ears, nose and throat show nothing unusual. The chest is broad and deep; the abdomen rounded and the genitalia and extremities are normal.

Section.-The skin is thin and the panniculus adiposus quite thick, lightyellow and moist. The muscles are of a deep red color. The sternum, costal cartilages and ribs are normal. The lungs lie free in the pleural cavities. There are no adhesions, but in the left pleural cavity are about 20 c.c. of a clear yellowish tluid. The thymus is not enlarged. The mediastinal lymphnodes are of the usual size. The right side of the heart is dilated.

Pericarlium: The pericardium is thin, smooth and glistening. There are no adhesions. The pericardial sac contains 5 c.c. of a clear, yellowish fluid. The heart weighs 18 grams; the right auricle and ventricle are considerably dilated and contain dark fluid blood and soft clots. The left auricle is slightly dilated; the left ventricle is firmly contracted. The endocardium throughout is smooth and glistening; the valves show no aknormality. The myocardium of the left ventricle is considerably thicker than usual.

Lungs: The entire right and the upper lobe of the left lung are air-containing throughout. The lower lobe of the left lung, however, is considerably increased in consistency. On pressure it pits slightly and is not crepitant. The pleura is roughened and is of dull red color. Over its surface are a few strands of fibrinous exuclate. On section it cuts easily; the cut surface is moist, dark red, and slightly granular. On pressure there exudes a dark red, slightly frothy fluid. Macroscopically the bronchi and vessels show nothing unusual.

Larynx and Trachea: On removing the larynx and on external inspection, it appears quite normal. On looking down between the vocal cords, however, marked changes are found. Instead of the characteristically shaped chink between the true vocal cords, there is only a very small slit-like aperture with granular edges. On opening the larynx over the anterolateral portion of the wall and extending from the true vocal cords down to the third ring of the trachea, there is a reddish-gray growth with quite an irregular and granular surface. Opposite the lower border of the thyroid cartilage there is a slightly larger growth of a deeper red color and with a more irregular surface. The lumen of the laryn and upper part of the trachea is greatly narrowed by this growth. The greatest narrowing is at the true vocal cords where the opening measures 1.5 by $3 \mathrm{~mm}$; the diameter of the larynx, just below the cords from cartilage to cartilare is $9 \mathrm{~mm}$. The thickness of the mucosa at this point is $3 \mathrm{~mm}$. The point of the greatest thickening is at the lower border of the thyroid cartilage, where the mucous membrane measures $4 \mathrm{~mm}$. The diameter of the lumen of the trachea below the growth is $8 \mathrm{~mm}$, while at the latter it is only $3 \mathrm{~mm}$., at the widest point.

Microscopical Examination.-The heart, aorta, thymus and mediastinal glands show no remarkable pathologic changes. The lower lobe of the left lung shows an early lobar pnelumonia.

Larynx: The pathologic changes in the larynx are confined to the mucosa and show marked differences in the various regions. Just below the vocal cords there is a great thickening of the mucosa. This depends on an increase in all of the elements, but more especially in the fibrous connective tissue. Towards the lumen the tissue is densely infiltrated with mononuclear leukocytes and plasma cells. Thin-walled engorged vessels are quite numerous and the mucous glands, which normally in this region are rather small, are quite large and show evidences of an active hyperplasia. In places they are considerably distorted by the overgrowth of the surrounding connective tissue. The lumina of the glands and their ducts are filled with a faintly basic-staining 
homogeneous material in which a few mononuclear cells are found. The gland cells stain deeply and the nuclei are very large. The epithelium of the larynx is absent in not a few regions, and here the tissue is densely infiltrated with round cells and the surface is covered by a smail amount of a cellular exudate. The tissue in this region is quite edematous.

Sections made from portions of the larynx lower down show varying grades of gland and connective tissue, hyperplasia and chronic catarrhal changes. Here also thin-walled vessels are quite prominent.

Near the lower border of the thyroid cartilage in the region which macroscopically appeared of a deeper red than elsewhere, very interesting changes are found. Here, as in other portions of the laryngeal mucosa, the glandular elements are hyperplastic, but instead of being imbedded in an edematous, infiltrated, fibrous, connective tissue, they are compressed and distorted by what appears to be a true hemangioma simplex. The main portions of the tissue is composed of numerous, small tortuous vessels with thin walls and quite prominent endothelium which in places seems to be more than one layer in thickness. The vessels lie very near each other, the interstitial tissue being composed of numcrous spindle shaped cells. All the vessels are filled with blood.

In a critical review of the literature we have been able to find twentysix undoubted cases of angioma of the larynx. These, with our own case, bring the total to twenty-seven. Cases have been reported by various authors which can hardly be classed among the true angiomata. Among these may be mentioned a case by Hooper ${ }^{1}$ of a richly vascular papilloma of cavernous structure, and another of Fedele, ${ }^{2}$ which proved to be a fibro-angioma of the right vocal cord. Eppinger ${ }^{3}$ has described a case of fibroma hemangiectaticum of the larynx that could not be included in the series. Vitto-Massei ${ }^{4}$ has reported a case of large gray tumor of the left sinus pyriformis in a man, 50 years of age, which proved to be a connective tissue growth poor in cells and containing cavernous bloodspaces. A varix of the left aryteno-epiglottidean fold has been reported by Juffinger. ${ }^{5}$ Wingrave, ${ }^{6}$ in a study of fifty cases of innocent laryngeal growths, encountered ten cases of angiofibroma and one of angiomyxoma. Hirsch, ${ }^{7}$ in describing one true angioma, mentions two other cases in which the tumors were richly vascular, but he himself did not think they could be included among the true angiomata.

No age is exempt, but the majority of cases occur during middle life. The oldest recorded case was in a patient 62 years of age, and the youngest was our own, which was 9 months. The proportion of males to females is approximately four to one.

1. Hooper: Med. Rec., New York, 1884, xxv, 562.

2. Fedele: Osservatore, Gaz. d. clin. di Torino, 1878.

3. Eppinger: Path. Anatomie des Larynx und der Trachea, Aug. Hirschwald, Berlin, 1880.

4. Vitto-Massei: Internat. Centralbl. f. Laryngol., Rhinol., etc., Berlin, 1907, xxiii, 68 .

5. Juffinger: Wien. klin. Wehnschr., 1891, xlii, 760.

6. Wingrave: Jour. Laryngol., Lond., 1906, xxi, 215.

7. Hirsch: Wien. klin. Wehnschr., 1908, xxi, 562 . 
HTIOLOGY

The etiology of angioma of the larynx is obscure. Chiari ${ }^{8}$ brings up the question, as do many authors, as to whether the angiomata do not directly follow a chronic hyperemia and catarrh of the laryngeal mucosa. Grant ${ }^{9}$ states that such growths as fibromata, fibropapillomata, fibroadenomata, cysts and angiomata are best explained as the results of inflammatory conditions. In many cases he says the sequence of events is from an acute to a chronic inflammation, with such subsequent hyperplasia as to constitute a tumor. Pegler, ${ }^{10}$ in discussing the cases of Symonds ${ }^{11}$ and St. Clair Thomson, ${ }^{12}$ thought that angiomata were granulomata with dilated capillaries and admixture of fibrous tissue. In favor of the prevailing supposition that angiomata of the larynx follow inflammatory conditions is the fact that there is a history of the latter in almost every case. The preponderance of males, who from exposure are more subject to laryngeal catarrh than the opposite sex, would be confirmatory evidence. In our own case a laryngitis accompanying measles was present three months before the symptoms referable to the tumor were noticed. From this observation, together with a critical review of the reported cases, we feel justified in assuming that the majority of cases of angioma of the larynx are the result of a previous inflammatory condition.

Symptoms and Diagnosis.-There are two types of angioma of the larynx, viz., angioma simplex and angioma cavernosum. The latter type is much more common. The angioma simplex generally occurs as a fiattened tumor, while the angioma cavernosum has a roughened surface. All authors agree that great care must be taken in the diagnosis of these tumors, as not infrequently vascular papillomata, fibromata, and especially varices are erroneously called angiomata.

In the majority of cases the symptoms at the time the patient comes under observation are well marked. In the discussion of the etiology of angiomata of the larynx, we alluded to the fact that in a large number of the patients there was a history of chronic laryngitis, often extending over a period of years. The most frequent symptoms are cough, hoarseness, feeling of foreign body in the larynx, aphonia, difficulty of breathing and expectoration of mucus often streaked with blood. Occasionally, as in our own case, the larynx may be almost completely obstructed, and thus cause death. Loomis reports one case in which very serious hemorrhage

8. Chiari: Arch. f. Laryngol, u. Rhinol., 1896, v, 100.

9. Grant: Jour. Laryngol., Lond., 1904, xix, 637.

10. Pegler: Jour. Laryngol,, Lond., 1905, xx, 337.

11. Symonds: Jour. Laryngol., Lond., 1905, xx, 337.

12. St. Clair Thomson: Jour. Laryngol., Lond., 1905, xx, 337. 
occurred. The diagnosis is usually easy from laryngoscopic examination, if the age and condition of the patient permits; in our own case this was impossible.

\section{TREATMENT}

The treatment consists in the removal of the tumor, which usually can be easily accomplished by the galvano-cautery or other measures. The hemorrhage is usually not troublesome.

\section{ABSTRACTS OF REPORTED CASES}

The following cases we have abstracted from the literature:

Fauvel : ${ }^{13}$ Male, aged 53, of good general health; complained of hoarseness, without cough or pain. A non-pedunculated red tumor, of black color in spots, was found situated in the angle of the vocal cords. The tumor was about the size of a filbert, and was successfully removed.

Coupard ${ }^{14}$ reports an angioma of the vocal cord, but the paper was not available.

Heinze : ${ }^{15}$ Male, aged 38, of poor health, being anemic and weak. Had long-standing pharyngeal and laryngeal catarrh with hoarseness. A tumor the size of half a lentil was found at the border of the right ventricular fold, near the anterior commissure. Behind this, separated by a free interspace, there was another tumor of about one-half the size of the previous one. Both were reddish-black in color, round and uneven. They were successfully removed at operation.

Elsberg: ${ }^{16}$ Male, aged 37 ; complained of increasing hoarseness of six years' duration. For twelve years had a nasopharyngeal catarrh which he thought had gradually involved the larynx. At time of examination there was a slight hoarseness and considerable mucus in throat, but no pain. A tumor the size of a pea was found attached by a thin, dark pedicle to the right vocal cord near the anterior commissure. This on microscopic examination was found to be an undoubted cavernous angioma.

Elsberg: $:^{16}$ Male, aged 28; had had whooping-cough and diphtheria in infancy, and for many years had catarrh. For the previous five years, after excessive use of voice, he became aphonic. Gradually he became very hoarse, and on examination, a tumor of the vocal cord was found. This tumor was reddish-black in color, smooth and pyriform in shape. It was attached to the edge of the right vocal cord and extended from the anterior commissure back for at least one-third of the length. The diagnosis was angioma and it was successfully removed.

13. Fauvel: Traite pratique des maladies du larynx, v, Adrien Delahaye et Cie., 1876, 545.

14. Coupard: Rev. mens. d. laryngol., 1880-81, i, 311.

15. Heinze: Arch. Laryngol., 1880, i, 135.

16. Elsberg: Arch. Med., 1884, xi, 12. 
Kidd : ${ }^{17}$ Female, aged 50 ; complained of loss of voice, which progressed gradually during a period of eight or more years. The tumor was small, oval, imperfectly bi-lobed, dark red and finely granular. It sprang from the upper surface of the left vocal cord. Microscopic examination showed it to be a true angioma.

Seiler ${ }^{18}$ reports case of true angioma of right vocal cord (quoted by Wolfenden).

Thurber: ${ }^{19}$ Male, aged 31 ; complained of hoarseness, developing after a cold, three years before examination. He had no dyspnea. One year after hoarseness developed he had an attack of laryngitis, during which time he spit up some bloody mucus. Examination revealed a purplish tumor, half an inch in diameter covering the laryngeal opening, but not interfering with motion of the vocal cords. The microscopic diagnosis was angioma.

Wolfenden : ${ }^{20}$ Male, aged 44 ; complained of hoarseness and at times a sensation of foreign body in the larynx, with dryness of the throat, with occasional expectoration of blood. Examination revealed a large bright red tumor, situated on the surface and edge of the right ventricular band, occupying the posterior two-thirds, and completely hiding the vocal cord except at its anterior third. The growth had the appearance of a small raspberry. A second much smaller growth of similar appearance was found at the anterior extremity of the left vocal cord. The breathing was never interfered with. The tumor was not operated on.

Schwarz ${ }^{21}$ (quoted by Wolfenden) has reported a case of submucous capillary angioma of the larynx.

Desvernine :22 Male, aged 53; complained of occasional bleeding from the throat and at one time had a severe hemorrhage. Examination showed a pedunculated angioma of the epiglottis.

Brown: $:^{23}$ Male, aged 26; complained of uneasy sensation for three weeks. The upper surface of both vocal cords was a dusky red color, and the entire interlaryngeal mucous membrane was hyperemic. The secretions were increased, and on the left ventricular band, occupying almost its entire upper surface, was a somewhat oval-shaped vascular tumor of a uniform gray color except in the center, which was bright red, becoming purple after repeatedly phonating. The patient was not treated.

$\mathrm{Beau}^{2+}$ (quoted by Chiari) reports two cases of angioma of the larynx.

17. Kidd: Brit. Med. Jour., 1888, i, 584.

18. Seiler (quoted by Wolfenden) : Jour. Laryngol., Lond., 1888, ii, 291.

19. Thurber: Laryngoscope, 1911, xxi, 878.

20. Wolfenden: Jour. Laryngol., Lond., 1888, ii, 291.

21. Schwarz (quoted by Wolfenden): Jour. Laryngol., 1888, ii, 291.

22. Desvernine: Revista de ciencias Medicas, 1888.

23. Brown: Jour. Respir. Org., 1889, i, 40.

24. Beau (quoted by Chiari): Arch. f. Laryngol. u. Rhinol., 1896, v, 100. 
Ioomis:25 Female, aged 62 ; had a tumor the size of an English walnut on the side of the tongue, one involving the left side of the pharynx and another in the neck. These had been present since birth. Eight months later the patient was seen, and at that time was in a critical condition, with eyanosis of the face, intense dyspnea and difficulty of speech. Six hours before death she passed per rectum 16 ounces of blood. At autopsy, in addition to the tumors of the tongue, pharynx and neck, there was found two angiomatous tumors of the larynx, one the size of a large pea, projecting from the ventricle of the laryn $\mathrm{x}$ on the left side, and the other the size of a cherry at the lowest part of the aryteno-epiglottidean fold.

Fauvel $:^{26}$ Male, aged $3 \%$; suffered with severe hoarseness, lasting sevcral months, with sudden attacks of aphonia without appreciable cause. A pea-sized tumor, blackish-red, smooth and slightly pedunculated, was situated on the free edge of the left vocal cord near its anterior insertion so as to prevent approximation of the cord. It was removed at operation with complete cure. The microscopic examination showed it to be a cavernous angioma.

Mackenzie $^{2 \tau}$ observed two cases of angioma of the larynx. Both were of blackberry-like appearance in color, form and size. One grew in the right hyoid fossa and the other in the right ventricular band.

Chiari $:^{8}$ Male, aged 28 ; complained of throat trouble. On examination there was a chronic catarrhal pharyngitis and marked hyperemia of the laryngeal mucosa. A bluish nodule the size of a hempseed was found on the right vocal cord. Chiari was inclined to think this was a rarix after a complete microscopical examination, but Billrotl, in the discussion, thought that it was a cavernous angioma.

Brady:-2 Boy, age not given; complained of dyspnea, hoarseness and expectoration of blood. A cherry-sized, deep red, rough tumor was found below the anterior commissure of the rocal cords. The tumor bled easily. It was successfully removed and proved to be an angioma.

Symonds:11 Male, aged 30; had recurring colds in his head followed by hoarseness and sensation of lump in the larynx on the right side. A purple, vascular, hard, lobulated swelling was found on the right side overhanging, but not involving the cord. The ventricular band was lost in the swelling and the anterior edge of the vocal cord was just visible on phonation. The diagnosis was angioma.

'Thomson ${ }^{12}$ (in discussion of Symond's case) said that he had seen a similar growth in a patient 25 years of age, in which there was a bluish

25. Loomis: Proc. New York Patlı. Soc., 1890, p. 30.

26. Fauvel: Traite pratique des maladies du larynx, v, Adrien Delahaye et Cie., 1876, p. 606.

27. MacKenzie: Diseases of the 'Throat and Nose, Presley-Blakiston, Phila., 1s80, i, 307.

28. Brady: Jour. Laryngol., 1901, xvi, 14. 
infiltration under the ventricular band. There were no symptoms except when treated.

Malzeu $^{29}$ described a case in which a tumor weighing 14 grams, situated on the arytenoid cartilages, hung down into the entrance of the larynx. The examination showed a cavernous angioma.

Hirsch $:^{7}$ Female, aged 22 ; complained of hoarseness. A tumor involving the whole right cord and another on the anterior third of the left cord, including the ventricle, was found. Both tumors were bluish-red, and about the size of a raspberry. The surface of the right was warty, the left smooth. The diagnosis was hemangioma cavernosum.

Glasgow: ${ }^{30}$ Patient had complained of hoarseness for six months. There was a slight impediment of speech. At times there was a sudden break in the voice, which was cleared by a short cough. Iaryngoscopic examination showed a grayish-brown lobulated tumor, the size of a large pea attached to the left vocal cord. The diagnosis was angioma cavernosum.

Ferreri ${ }^{31}$ (quoted by Glasgow) reports a case of angioma the size of a hazel-nut situated on the inferior part of the left vocal band. This was crushed by means of forceps, and despite the application of ferric chlorid and a tracheotomy, violent hemorrhage took place. Death from pneumonia ensued within forty-eight hours.

3849 Prospect Avenue.

29. Malzeu: Mitt. der Baz. Klinik, 1907, ii, 56.

30. Glasgow: Amer. Jour. Med. Sc., 1889, xevii, 300.

31. Ferreri (quoted by Glasgow): Amer. Jour. Med. Sc., 1889, xevii, 300. 